\title{
Research on the Characteristics of GIS-based Industrial Agglomeration in Shenyang
}

\author{
Zuo Ying ${ }^{1}$, Chen Chen ${ }^{2, *}$ \\ ${ }^{1}$ College of Urban and Environmental Sciences, Northwest University, Xi'an 710127, Shaanxi; \\ ${ }^{2}$ Institute of Human Geography, School of Tourism, Xi'an International Studies University, Xi'an, Shaanxi 710128, China
}

\begin{abstract}
Research on industrial agglomeration using GIS spatial analysis and spatial visualization technology is still relatively few, so do the research on industrial agglomeration at the micro-spatial scale within the city. Based on the data of the legal entity of the street (township), using the Tsui-Wang Index and GIS methods, the spatial agglomeration characteristics of the secondary and tertiary industries in Shenyang are discussed from the three aspects of industrial spatial polarization, spatial differentiation and spatial correlation, and it is found that (1) there is a certain degree of polarization in various industries, with different degree of polarization of different industries, and the degree of polarization of the tertiary industry is slightly higher than that of the secondary industry; (2) the industrial spatial heterogeneity is obvious, showing spatial differentiation; (3) various industries have a certain degree of spatial correlation, but the overall degree of correlation is low, and the spatial correlation of the tertiary industry is slightly higher than that of the secondary industry; (4) there are obvious hotspots and cold spots in the industrial distribution, the secondary industry hotspots are distributed in the northern and western new cities, while the urban core areas are cold spots. The tertiary industry hotspots are concentrated in the urban core areas, while the cold spots are located at the south of the city. Inside the secondary and tertiary industries, except for the production and supply of electricity, heat and water, other industries have obvious hot and cold spots. Therefore, it can be considered that the industrial distribution has certain agglomeration characteristics, but the degree of agglomeration is not high, and the degree of agglomeration of the tertiary industry is slightly higher than that of the secondary industry.
\end{abstract}

\section{INTRODUCTION}

One of the basic characteristics of the world industrial organization is the spatial agglomeration of similar or related industries ${ }^{[1]}$. The famous economist Krugman believed that "Industrial spatial agglomeration is the most prominent geographical feature of economic activities ${ }^{[2]}$." Industrial agglomeration has promoted the rise of important economic centers around the world, for example, Silicon Valley in the United States draws attention of hightech companies, New York's financial industry gathers on Wall Street, the headquarters of most major Japanese companies are located in Tokyo and Osaka. In the eastern coastal areas of China, agglomeration of enterprises has become an important factor in promoting economic development ${ }^{[3]}$. Industrial agglomeration has always been one of the important topics in geography, economics and other disciplines.

At present, foreign research results on industrial agglomeration have been quite rich, including the relevant theories of industrial agglomeration, the influencing factors of industrial agglomeration and the effect of industrial agglomeration. Many geographers discovered the phenomenon of industrial agglomeration early, and formed classical theories such as Marshall's classical location theory, Weber's industrial location theory, and Losch's location theory. The externalities produced by agglomeration ${ }^{[4]}$, the degree of spatial dispersion or concentration of factor endowments ${ }^{[5]}$, economies of scale ${ }^{[6]}$, and the reduction of trade costs ${ }^{[7]}$ are considered to be the factors affecting industrial agglomeration. Industrial agglomeration has many positive effects, such as driving industrial growth, conducive to the improvement of its innovation ability ${ }^{[8]}$, boosting factor productivity ${ }^{[9]}$, and promoting the formation of good industrial locations ${ }^{[10]}$.

Before the reform and opening up, China's planned economic system implemented a balanced distribution of productivity, and there was very little industrial agglomeration. Since the reform and opening up, China's economy has developed rapidly, with more and more obvious phenomenon of industrial agglomeration. Industrial agglomeration has attracted the attention of some scholars, and the researches mainly focus on the influencing factors and measurement methods of industrial agglomeration. Zhu Huasheng et al. conducted research on the Dongguan's electronic information industry cluster and found that the main factors affecting the local connections of enterprises are industrial factors, enterprise factors, local factors, and psychological factors

*E-mail: 87086559@qq.com 
[11]. Tong Xin et al. studied the spatial evolution of Dongguan's computer industry clusters [12]. After synthesizing many scholars' researches on enterprise clusters, Qiu Baoxing defined small business clusters, and considered that the reason for its formation was the "alliance" formed by small enterprises to change their own living environment ${ }^{[13]}$. He Canfei found that China's manufacturing industry is becoming more and more concentrated in space. Economic globalization, comparative advantages, and economies of scale are the reasons for the spatial concentration of industries. The external economy has not promoted the geographical concentration of industries, while fierce intra-industry market competition has promoted the industry to be scattered in space ${ }^{[14]}$. Li Guoping and Sun Tieshan et al. studied the agglomeration process of Beijing's high-tech industries and discussed its influencing factors with the aid of the diamond model ${ }^{[15]}$. Wu Fenglin and Fang Chuanglin et al. used the thought of system theory to summarize the general ideas of the research on the urban industrial agglomeration dynamic mechanism and agglomeration mode. They pointed out that the regulation system can guide the development of urban industrial agglomeration in a regulating way, which is of practical significance for the government to plan and guide the development of urban industrial economy ${ }^{[16]}$. The PAF model constructed helps to analyze the size and combination of industrial agglomeration powers of different cities in a specific area ${ }^{[17]}$. Ma Yanji once summarized the research progress of regional industrial agglomeration mechanism, agglomeration structure, agglomeration law, etc., and put forward the shortcomings of the research on industrial agglomeration in China, and provided a more systematic research framework for industrial agglomeration ${ }^{[18-19]}$. Liu Chunxia once systematically summarized the measurement methods of industrial geographic concentration, which promoted the correct understanding and application of these methods ${ }^{[20]}$. Qiu Ling and Fang Chuanglin used a series of industrial agglomeration measurement indicators to conduct a comprehensive measurement of the spatial agglomeration of the producer service industry in Beijing from 1996 to 2008, achieving the comparison of the degree of industrial agglomeration of different spatial scales, different time nodes, and different types of industries ${ }^{[21]}$. In addition, the spatial characteristics of industrial agglomeration have also attracted some scholars' attention. Fan Ying discussed the distribution characteristics and trends of industrial clusters in Northeast China based on the data of the two national economic censuses ${ }^{[22]}$. Lu Rui et al. studied the characteristics of agricultural industrial clusters in the Hexi Corridor based on the enterprise agglomerationsocial network-service system ${ }^{[23]}$.

In summary, domestic research on industrial agglomeration has formed more research results on the basis of learning from foreign research experience. However, the research on industrial agglomeration using GIS spatial analysis and spatial visualization technology is still relatively few. In addition, the research on industrial agglomeration at the micro-scale of urban internal space is still insufficient. This paper is based on the third economic census' data from street legal entities, using GIS spatial analysis and spatial visualization techniques, and referencing more mature measurement indicators from the researches on industrial agglomeration. Taking Shenyang as an example, it reveals its results from the microscopic spatial scale within the city. The spatial agglomeration characteristics of the secondary and tertiary industries will enrich the research results of urban industrial agglomeration and provide a basis for the optimization of Shenyang's industrial layout.

\section{RESEARCH AREA, DATA SOURCES AND RESEARCH METHODS}

\subsection{Research Area}

The research area is the central city of Shenyang, including Shenhe District, Heping District, Tiexi District, Huanggu District, Dadong District, Yuhong District, Shenbei New District, Sujiatun District, and Dongling District, with a total area of $1219.208 \mathrm{~km} 2$ and a total of 95 streets. The economic activities in the study area are mainly non-agricultural economic activities, so this study does not consider the primary industry. The basic spatial unit of the study is the street. The central city of Shenyang is divided into the urban functional core area (the central old city) and the function expansion area according to Urban Master Planning of Shengyang City (2011-2020). The expansion area is further divided into three areas: Hunnan New City, Northern New City, and Western New City. Hunnan New City is the core area of the city for service functions and the development area of emerging industries, and the west and north are the expansion areas for the city's core production functions (Figure 1).

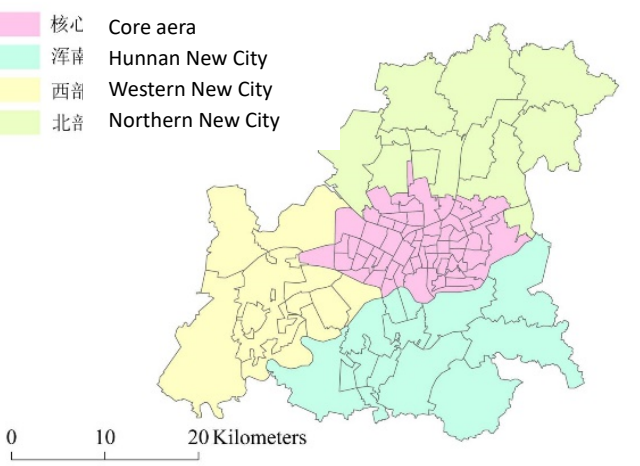

Figure 1 Functional subareas of central city in Shenyang

\subsection{Data Sources}

This paper analyzes the characteristics of industrial spatial agglomeration in Shenyang based on the number of legal entities in the secondary and tertiary industries in each street. The data come from the third economic census of Shenyang. According to the national economic industry classification standards, the secondary industry is divided into three categories, i.e., manufacturing, electricity, heat and water production and supply, and construction. The tertiary industry is divided into three categories, i.e., circulation sector, production and living service sector, 
and service sector that improves the level of science and culture and the quality of residents.

\subsection{Research Methods}

\subsubsection{Tsui Wang Index}

Based on the Wolfson Index, Tsui Kai-yuen and WangYou-qiang used the two partial ordering axioms of increased polarization and increased diffusion to derive a new set of polarization measurement indexes, called TsuiWang Index (TW Index for short, or Cui Wang Index) [24]. Its expression formula is

$$
T W_{j}=\frac{\theta}{D} \sum_{i}^{n} \pi_{i}\left|\frac{x_{i j}-m_{j}}{m_{j}}\right|^{r}
$$

Where, TWj is the Tsui Wang index of $\mathrm{j}$ industry; $\theta$ is a constant greater than zero; $r$ is any value in $(0,1)$; here, $\theta$ and $r$ are both $0.5 . \mathrm{n}$ is the number of geographic areas (the number of streets here); $\mathrm{D}$ is the total population; $\pi \mathrm{i}$ is the population of street $i$; $i j$ is the number of $j$ industrial legal entities in street $\mathrm{i}$; mij is the median of number of $\mathrm{j}$ industrial legal entities in $\mathrm{n}$ geographic areas. TW is between 0 and 1 . The larger the TW index, the more prominent the regional polarization phenomenon.

\subsubsection{GIS Method}

\subsubsection{Inverse Distance Weighted Spatial Interpolation.}

Inverse distance weighted (IDW) spatial interpolation is one of the most widely used spatial interpolation methods. It predicts unknown sample points based on the data of known sample points, and obtains a continuous spatial variation diagram and corresponding values of a certain geographic phenomenon in the entire region, and its spatial variation trend is continuous. This method is implemented by the Interpolation tool in ArcToolbox in ArcGIS software.

\subsubsection{Spatial Autocorrelation Model}

The spatial autocorrelation model is used to measure the degree of interdependence between geographic phenomena. The spatial autocorrelation model uses statistical methods to calculate the degree of spatial autocorrelation based on the characteristic value of a certain geographical phenomenon to analyze the spatial distribution characteristics of a certain characteristic value, including global spatial autocorrelation and local spatial autocorrelation models, which can be implemented using tools such as Spatial Autocorrelation (Morans I) in ArcToolbox in ArcGIS software.

Global spatial autocorrelation is used to describe the degree of spatial association of a certain geographic attribute. It is based on global statistics and is measured by Global Moran's I (Global Moran Index), with the value range of Global Moran's I between -1 and 1. Global
Moran' I $>0$ indicates spatial positive correlation, that is, similar observations tend to be spatially clustered. The larger the value, the higher the degree of clustering; Global Moran' $\mathrm{I}<0$ indicates spatial negative correlation, that is, scattered distribution, and Global Moran' I $=0$ means that the space is not correlated, that is, randomly distributed.

The local spatial autocorrelation model can describe the level of spatial autocorrelation on a local scale and reveal the spatial heterogeneity of geographic phenomena. This paper uses the local $\mathrm{G}$ statistic $\mathrm{Gi}^{*}$ to measure. When the local $\mathrm{Gi}^{*}>0$, and the larger the value, it means highvalue aggregation, that is, a certain geographic phenomenon has the characteristics of hot spot distribution; when $\mathrm{Gi}^{*}<0$, and the smaller the value, it indicates low-value aggregation, that is, a certain geographic phenomenon has the characteristics of cold spot distribution.

\section{RESULT ANALYSIS}

\subsection{Industrial Polarization Characteristics}

The TW index of each industry sector is shown in Table 1. Generally speaking, there is a certain degree of polarization in various industries, and the degree of polarization in the tertiary industry is slightly higher than that in the secondary industry. Within the tertiary industry, the TW index of the production and living services sector reaches the highest $(0.519)$, with the most obvious polarization, while the science and education service sector have the lowest TW index (0.369), and the circulation sector was basically the same as the tertiary industry TW index. Among the secondary industries, the construction industry has the highest TW index (0.412), and the electricity, gas and water production and supply industries have the lowest TW index. This means that although the degree of polarization in the construction industry is not as high as that in the tertiary industry, it exceeds the average level of the secondary industry.

\begin{tabular}{lc}
\multicolumn{2}{c}{ TAB.1 INDUSTRIAL TW INDEX } \\
\hline TW Index \\
\hline Secondary Industry & $\mathbf{0 . 4 0 2}$ \\
Manufacturing & 0.409 \\
Electricity, gas and water production and & 0.386 \\
supply industries & 0.412 \\
Construction & $\mathbf{0 . 4 3 4}$ \\
Tertiary Industry & 0.431 \\
Circulation & 0.519 \\
Production and Living & 0.369 \\
Science and education service & \\
\hline
\end{tabular}

\subsection{Industrial Spatial Differentiation Characteristics}

Using ArcGIS to perform inverse distance weighted spatial interpolation on the unit number of legal entities in the secondary industry and tertiary industry in each street, the spatial differentiation characteristics of the industry can be obtained. The result is shown in Figure 2. 


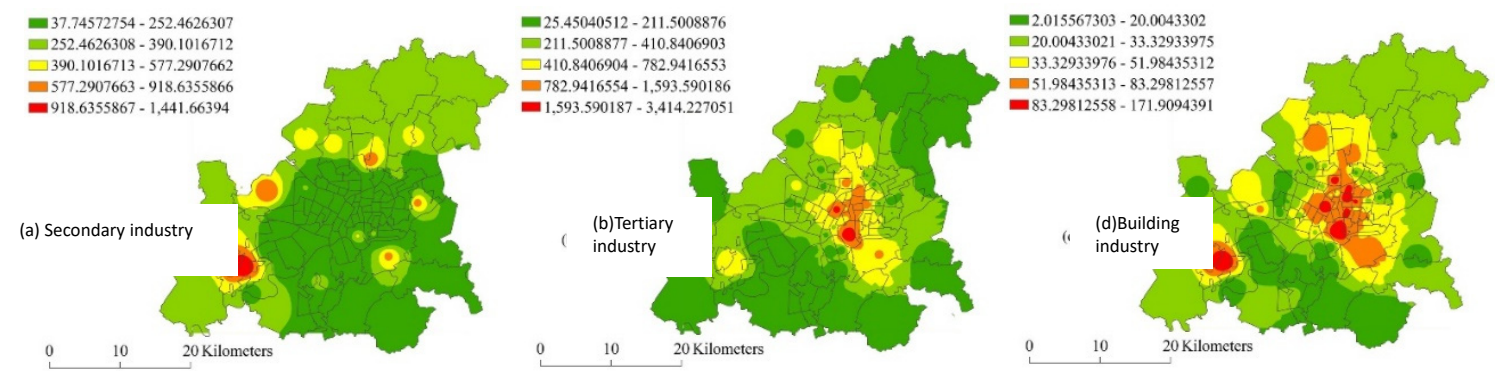

Figure 2 Industrial spatial differentiations

Overall, the industrial spatial heterogeneity is obvious, showing spatial differentiation. The secondary industry is mainly distributed in the west and north of the city. The west and the north are the new western and northern new cities in urban planning, which are important carriers and functional expansion areas for undertaking industries in the urban core area. Under the guidance of urban policies and planning, with the implementation of the city's "retreat from two to three" strategy and the expansion of industrial scale, the secondary industry clusters in the west and north of the city, and the urban core area that can provide a large amount of service demand and central location becomes the third industrial cluster area. The construction industry is concentrated in the core area of the city and the new towns in the north, west and south, with the characteristics of agglomeration of the secondary industry and the tertiary industry. This is mainly due to the fact that the city is in a large-scale construction stage. There are a large number of construction activities in the core areas and new urban areas, such as housing construction, construction installation, construction decoration and other construction industries.

\subsection{The Characteristics of Industrial Spatial Correlation}

\subsubsection{Global Relevance of Industrial Space}

Using ArcGIS software of global Moran index to calculate global Moran index of various industries, with the results shown in Table 2. Except for the production and supply of electricity, heat and water, the global Moran indices of other industries are all positive (passing the significance test at the 0.01 level), that is, there is correlation among the number of legal entities in various industries on the spatial scale of the street (township), i.e., the high-density area is adjacent to the high-density area while the lowdensity area is adjacent to the low-density area, but the overall degree of association is low and slightly different. On the whole, the spatial correlation degree of the tertiary industry is higher than that of the secondary industry. Among them, within the secondary industry, the construction industry has a higher degree of correlation than the manufacturing industry and the production and supply of electricity, heat and water, showing the highest correlation, while the production and supply of electricity, heat and water has the lowest global Moran index. This means that this type of industry has a low degree of spatial correlation and presents a random distribution. Within the tertiary industry, the production and living service sectors have the highest degree of spatial correlation, while the circulation sector has the lowest degree of correlation. TAB.2 GLOBAL MORAN'S I

\begin{tabular}{lc}
\multicolumn{2}{c}{ TAB.2 GLOBAL MORAN'S I } \\
\hline \multicolumn{1}{c}{$\begin{array}{c}\text { Global } \\
\text { Moran's I }\end{array}$} \\
\hline Secondary Industry & $0.05^{* *}$ \\
Manufacturing & $0.11^{* *}$ \\
Electricity, gas and water production and & 0.01 Random \\
supply industries & $0.19^{* *}$ \\
Construction & $0.16^{* *}$ \\
Tertiary Industry & $0.11^{* *}$ \\
Circulation & $0.22^{* *}$ \\
Production and Living & $0.16^{* *}$ \\
Science and education service &
\end{tabular}

\subsubsection{Hot and Cold Spots in Industrial Space}

Using the local G statistics tool of ArcGIS software, the cold spots and hot spots of the spatial distribution of various industries can be obtained (Figure 3). The urban core area is the cold spot for the spatial distribution of the secondary industry, while the northern and western new cities, which are expansion areas of urban functions, are the hot spots for the spatial distribution of the secondary industry. Specifically, the distribution trend of cold spots and hot spots in the manufacturing industry is similar to that of the secondary industry. However, its GiZscore <$2.58 \mathrm{Std}$.Dev has a cold spot distribution area of $61.03 \mathrm{~km} 2$ in manufacturing, which is equivalent to twice the cold spot area of the secondary industry $(29.79 \mathrm{~km} 2)$. Compared with the secondary industry, the manufacturing industry is more inclined to be located in the function expansion areas outside the city, especially the two production function expansion areas in the northern new city and the western new city. There are no obvious hot or cold spots in the spatial distribution of electricity, heat and water production and supply industries. The reason is that the construction costs and demand thresholds (customer demand) of industrial sectors such as heating and power supply, coal gas, liquefied petroleum gas, natural gas transmission, water supply and drainage, etc. are high, the scope of services is large, and the industrial spatial layout tends to be scattered rather than clustered. In addition, contrary to the distribution of hot spots in the secondary industry, hot spots in the construction industry are concentrated in the core area of the city, while cold spots are located in the south and west of the city.

The hot spots of the tertiary industry are concentrated in the core area of the city, while the cold spots are located in the south of the city. The spatial distribution trend of hot and cold spots within the tertiary industry's internal 
circulation departments, production and living service departments, and science and education service departments is basically similar to that of the tertiary industry, and the distribution areas of hot and cold spots
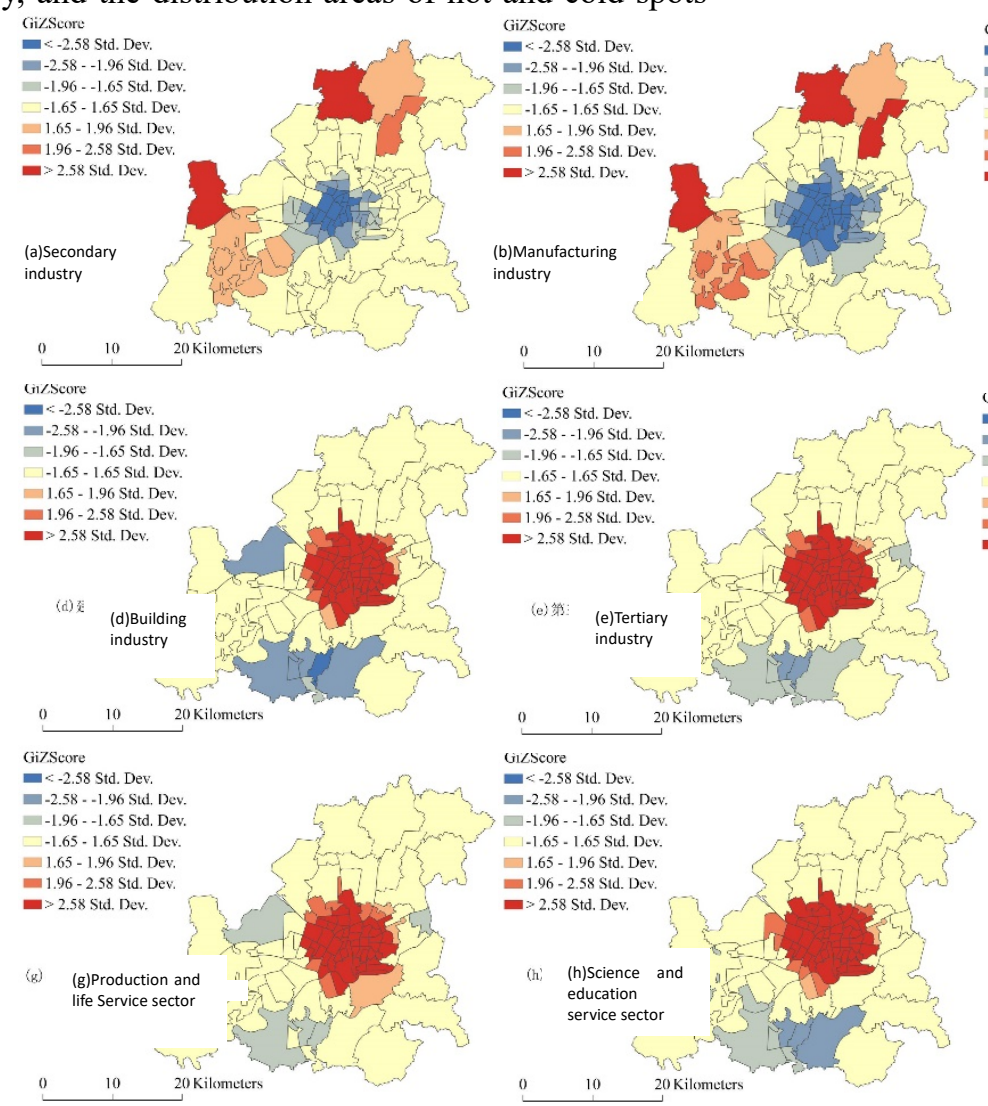

Figure 3 Cold spot and hot spot of industrial spatial distribution

\section{CONCLUSION AND DISCUSSION}

Based on the data of the legal entity of the street (township), using the TW index and GIS methods, the spatial agglomeration characteristics of the secondary and tertiary industries in Shenyang are discussed from the three aspects of industrial spatial polarization, spatial differentiation and spatial correlation, and it is found that (1) there is a certain degree of polarization in various industries, with different degree of polarization in different industries, and the degree of polarization in the tertiary industry is slightly higher than that in the secondary industry; (2) the industrial spatial heterogeneity is obvious, showing spatial differentiation; (3) various industries have a certain degree of spatial correlation, that is, high-density areas are adjacent to high-density areas, while low-density areas are adjacent to low-density areas, but the overall degree of association is low, and the spatial correlation of the tertiary industry is slightly higher than that of the secondary industry; (4) there are obvious hot and cold spots in the industrial distribution, the secondary industry hot spots are distributed in the northern and western new cities, while the urban core areas are cold spots; the tertiary industry hot spots are concentrated in except for the production and supply of electricity, heat the city core areas, while the cold spots are distributed in the south of the city. Within the second and third industries, are also alike. Different from the distribution of cold spots in the secondary industry, the tertiary industry and its sectors have no cold spots with GiZscore $<-2.58$ Std.Dev.

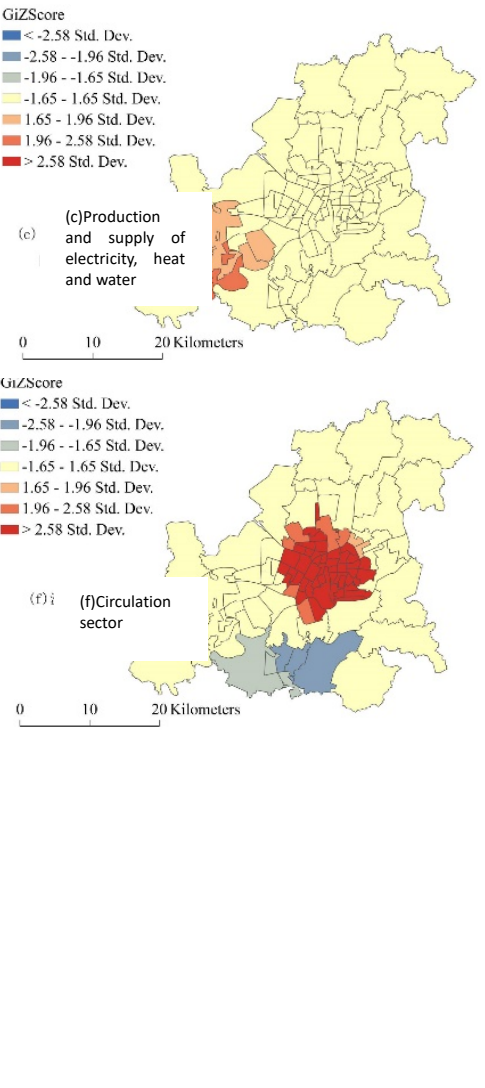

and water, other industries have obvious hot and cold spots. Based on the above research results, it can be concluded that the industrial distribution of Shenyang has certain agglomeration characteristics, but the degree of agglomeration is not high.

This research has certain shortcomings. On the one hand, the street is the basic space unit, and the street area ranges from a few square kilometers to tens of square kilometers. The large basic space unit makes it difficult to capture more microscopic features. On the other hand, due to limited data, only the number of legal entities is used without considering the size of the legal entities that may affect the accuracy of the research results.

\section{About the author}

Zuo Ying, male, from Xiaogan, Hubei, $\mathrm{PhD}$ candidate, engaged in research on urban and regional development

* Corresponding author: Chen Chen, female, Ph.D., lecturer, research interests of geography and GIS applications, E-mail: 87086559@qq.com

\section{REFERENCES}

1. Zhang Hua, Liang Jinshe. Research Progress on Industrial Spatial Agglomeration and Its Effects [J]. Progress in Geography, 2007, 26 (2): 14-24.

2. Krugman, P. Geography and Trade. Cambridge 
[M].MA: MIT Press, 1991.

3. Xu Qiang. Why Does Industrial Agglomeration Come into Being - Research on the Formation Mechanism and Development Countermeasures of Industrial Agglomeration in China [M]. Hangzhou: Zhejiang University Press, 2004.

4. Marshall, A. Principles of Economics: An Introductory (9th Ed)[M]. London: Macmillan, 1890.

5. Ohlin, B. Interregional and International Trade [J].Cambridge, MA: Harvard University Press, 1957.

6. Krugman, P. Scale Economies, Product Differentiation, and the Pattern of Trade[J].American Economic Review, 1980, (70): 950-959.

7. Hanson, G. H. North American Economic Integration and Industry Location [J].Oxford Review of Economic Policy, 1998, 14: 30-44.

8. Baptista, R. Geographical clusters and innovation diffusion [J].Technological Forecasting and Social Change, 2001, (66): 31-46.

9. Ciccone, A. Agglomeration effects in Europe [J].European Economic Review, 2002, 46: 213-227.

10. Head, K., Ries, J., Swenson, D. Agglomeration Benefits and Location Choice: Evidence from Japanese Manufacturing Investments [J].Journal of International Ecnomics, 1995, 38: 223-248.

11. Zhu Huasheng, Wang Jici. On the Influencing Factors of Local Connections within Industrial Agglomeration - Taking Dongguan Electronic Information Industrial Agglomeration as an example [J]. Economic Geography, 2002, 22 (4): 385-393.

12. TongXin, Wang Jichi. Development and Evolution of Local Industrial Clusters of PC-related Manufacturing Industries in Dongguan. Journal of Geographica Sciences [J], 2001, 56 (6): 722-729.

13. Chou Baoxing. Study on Small Business Agglomeration [M]. Shanghai: Fudan University Press, 1999.

14. He Canfei, Xie Xiuzhen. Geographical Concentration and Specialization of Manufacturing Industry in China [J]. Journal of Geographica Sciences, 2006, 61 (2): 212-222.

15. LI Guoping, SunTieshan, LU Minghua. Agglomeration Process of High-tech Industry in Beijing and its Influencing Factors [J]. Journal of Geographica Sciences, 2003, 58 (6): 927-936.

16. Wu Fenglin, Fang Chuanglin, Zhao Yaping. Research Progress on Dynamic Mechanism and Mode of Urban Industrial Agglomeration [J]. Progress in Geography, 2010, 29 (10): 1201-1208.

17. Wu Fenglin, Fang Chuanglin, Zhao Yaping. PAF Model for the Study of Dynamic Mechanism and Model of Urban Industrial Agglomeration [J]. Geographical Research, 2011, 30 (1): 71-81.

18. Ma Yanji. Research Progress on Regional Industrial Agglomeration [J]. Scientia Geographica Sinica, 2005, 25 (2): 226-231.

19. Ma Yanji. Preliminary Study on the Theory of
Regional Industrial Agglomeration [J]. Scientia Geographica Sinica, 2007, 27 (6): 756-760.

20. Liu Chunxia. Research on the Measurement Method of Industrial Geographical Concentration [J]. Economic Geography, 2006, 26 (5): 742-747.

21. Qiu Ling, Fang Chuanglin. Comprehensive Measurement of Spatial Agglomeration of P[roducer Services in Beijing [J]. Geographical Research, 2013, 32 (2): 99-110.

22. Fan Ying, Gu Hengyu, Meng Xin, et al. Spatial Pattern Analysis of Industrial Agglomeration in Northeast China - Based on micro-data of enterprises in two national economic censuses [J]. Areal Research and Development, 2019, 38 (3): 18-22.

23. Lv Rui, Shi Peiji. Identification and Evaluation of Agricultural Agglomeration in Hexi Corridor based on ESS model [J]. Areal Research and Development, 2019, 38 (3): 165-169.

24. Wang, Y., Tsui, K. Polarization Ordering and New Classes of Polarization Indices[J].Journal of Public Economic Theory, 2000, 3(2): 349-363 